\title{
Effects of Ion Bombardment Energy Flux on Chemical Compositions and Structures of Hydrogenated Amorphous Carbon Films Grown by a Radical-Injection Plasma-Enhanced Chemical Vapor Deposition
}

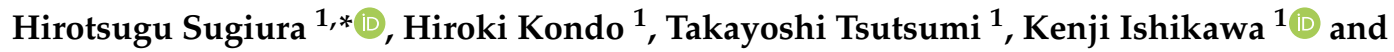 \\ Masaru Hori ${ }^{2}$ \\ 1 Graduate School of Engineering, Nagoya University, Furo-cho, Chikusa-ku, Nagoya 464-8603, Japan; \\ hkondo@nagoya-u.jp (H.K.); tsutsumi@plasma.engg.nagoya-u.ac.jp (T.T.); \\ ishikawa@plasma.engg.nagoya-u.ac.jp (K.I.) \\ 2 Institute of Innovation for Future Society, Nagoya University, Furo-cho, Chikusa-ku, Nagoya 464-8603, \\ Japan; hori@nuee.nagoya-u.ac.jp \\ * Correspondence: sugiura.hirotsugu@h.mbox.nagoya-u.ac.jp; Tel.: +81-52-789-3461
}

Received: 23 December 2018; Accepted: 18 January 2019; Published: 24 January 2019

check for updates

\begin{abstract}
Hydrogenated amorphous carbon (a-C:H) films have attracted much attention, because of their excellent physical and chemical properties, such as high mechanical hardness, chemical robustness, a wide variety of optical bandgaps, and so forth. Although an ion bombardment energy has been regarded as essential in the well-know subplantation model, it alone is inadequate especially in complicated reactions of a plasma-enhanced chemical vapor deposition process. In this study, an ion bombardment energy flux $\left(\Gamma_{E \mathrm{i}}\right)$ was proposed as a crucial factor to determine chemical compositions and structures of a-C:H films. To obtain the amounts of $\Gamma_{E \mathrm{i}}$, electron densities, hydrogen $(\mathrm{H})$ excitation temperatures, and negative direct current $(\mathrm{DC})$ self-bias voltage $\left(-V_{\mathrm{DC}}\right)$ were measured. The deposition rate increased, and $\mathrm{sp}^{2}-\mathrm{C}$ clusters incorporation was induced by the $\Gamma_{E \mathrm{i}}$. With increasing $\Gamma_{E \mathrm{i}}$, photoluminescence (PL) backgrounds in Raman spectra decreased, while spin densities in electron spin resonance (ESR) measurements increased. These results suggested the $\mathrm{H}$ content of a-C:H film decreased depending on the amount of $\Gamma_{E \mathrm{i}}$. The $\Gamma_{E \mathrm{i}}$ is one of the crucial factors to determine the properties of the a-C:H films.
\end{abstract}

Keywords: hydrogenated amorphous carbon (a-C:H); plasma enhanced chemical vapor deposition (PECVD); ion bombardment energy flux

\section{Introduction}

Amorphous carbon (a-C) films have attracted much attention, because of their excellent properties, such as high mechanical hardness, chemical inertness, a wide variety of optical bandgaps, and so forth [1-8]. The a-C films mainly consist of $\mathrm{sp}^{2}$ - and $\mathrm{sp}^{3}$-bonded carbons. Hydrogen $(\mathrm{H})$ content is also important when it is included in the a-C film, usually called hydrogenated a-C (a-C:H). Their properties strongly depend on the mixture ratios among $\mathrm{sp}^{2}-\mathrm{C}$ bonding states, $\mathrm{sp}^{3}-\mathrm{C}$ ones and $\mathrm{H}$ atoms Thus, controls of properties of a-C:H films have been studied from the viewpoint of how to control their chemical compositions and bonding structures.

A plasma-enhanced chemical vapor deposition (PECVD) is one of the commonly used methods and excellent in uniformity in large size wafer, coverage on high aspect patterns, and so forth. The a-C:H films deposited by the PECVD usually contain $\mathrm{H}$ atoms, because hydrocarbon molecular 
gasses are used as carbon precursors. To control their properties, the $\mathrm{C}-\mathrm{H}$ bonding is quite important. For example, it has been reported that the $\mathrm{H}$ content affects the hardness and density of the a-C:H films $[9,10]$. It has also been reported that the optical bandgap decreased with decreasing the $\mathrm{H}$ content of the films [11].

To date, in the well-known "ion subplantation model," which was first suggested by Lifshitz et al., the formation of $\mathrm{sp}^{3}$-bonded structures in a-C:H films was discussed as effects of ion bombardment with relatively high energies [12]. When the bombardment energy of carbon ions exceeds the penetration thresholds on the order of $30 \mathrm{eV}$, the ions can deeply penetrate the subsurface of the film [13]. At that time, the penetrating ions induce the displacement of hydrogen and break the chemical bonds between carbon and hydrogen, because the energy threshold for the displacement of hydrogen is only $2.5 \mathrm{eV}$ [14]. Furthermore, the model was established by Robertson and Davis $[15,16]$. The penetrated energetic carbon ions with a kinetic energy of around $100 \mathrm{eV}$ per atom densify the films, in which the local carbon-networks are augmented, and the carbon to carbon bonds are converted from $\mathrm{sp}^{2}$ to $\mathrm{sp}^{3}$ bonding structures [11]. When the ion energy excesses this threshold, a large fraction of the ion energy converts into heat within a small volume, called thermal spike, the density decreases, because of the stable energy state of $\mathrm{sp}^{2}-\mathrm{C}$ than $\mathrm{sp}^{3}-\mathrm{C}$, called relaxation. Miyagawa et al. also reported that dynamic Monte Carlo simulation for the deposition based on the subplantation model and it well represented experimental results [17].

In the case of the PECVD, the ion bombardment energy $\left(E_{\mathrm{i}}\right)$ can be controlled by the bias power, such as radio frequency (RF), direct current $(\mathrm{DC})$, and pulsed $\mathrm{DC}$, applied to the sample stage. The RF bias voltage is useful for not only conductive, but also insulative substrates, because the negative DC self-bias voltage $\left(-V_{\mathrm{DC}}\right)$ appears. The $E_{\mathrm{i}}$ is proportional to the magnitude of $-V_{\mathrm{DC}}\left(\left|-V_{\mathrm{DC}}\right|\right)$. Robertson et al. and Godet et al. reported that the $\mathrm{H}$ content and optical bandgap decreased with increasing the RF bias power [11,18]. However, the effect of ion flux $\left(\Gamma_{\mathrm{i}}\right)$ has not been discussed so far. Of course, larger amounts of ions are expected to desorb more hydrogen and develop densification and bond conversion. Oda et al. also reported the importance of the ratio between $\Gamma_{i}$ and radical flux in film hardness control from the simulation results [19]. Therefore, the $\Gamma_{i}$ should be considered as one of the essential factors as $E_{\mathrm{i}}$.

In this study, we investigated the effects of the ion bombardment energy flux $\left(\Gamma_{E \mathrm{i}}=\left|-V_{\mathrm{DC}}\right| \times \Gamma_{\mathrm{i}}\right)$ on the deposition rate, the incorporation of $\mathrm{sp}^{2}-\mathrm{C}$ clusters, the $\mathrm{H}$ content, and electronic properties of a-C:H films based on the plasma diagnostics results. To determine the $\Gamma_{E \mathrm{i}}$, the electron density, the $\mathrm{H}$ excitation temperature, and $-V_{\mathrm{DC}}$ were measured. The incorporation of $\mathrm{sp}^{2}-\mathrm{C}$ clusters, $\mathrm{H}$ contents, and electronic properties were discussed according to Raman spectra and electron spin resonance (ESR) measurements.

\section{Materials and Methods}

The growth of a-C:H films was performed using a radical-injection plasma enhanced chemical vapor deposition (RI-PECVD) system, in which two plasma sources were stacked and connected through a showerhead electrode [20,21]. Figure 1 shows the schematic diagram of RI-PECVD system. The upper plasma source for radical injection is surface wave plasma (SWP) generated by $400 \mathrm{~W}$ of $2.45 \mathrm{GHz}$ microwaves through a quartz window. The lower plasma source is dual-frequency capacitively coupled plasma (DF-CCP) generated by 20 and $250 \mathrm{~W}$ of a $100 \mathrm{MHz}$ very high frequency (VHF) power to the showerhead for controlling the radical generation. $13.56 \mathrm{MHz}$ RF power ranging from $30-150 \mathrm{~W}$ was applied to the sample stage for controlling $-V_{\mathrm{DC}}$ which related to the $E_{\mathrm{i}}$. To measure $-V_{\mathrm{DC}}$, an oscilloscope was connected to the lower electrode through the high voltage probe (P6015A, Tektronix, Inc., Beaverton, OR, United States) and low pass filter with a $20 \mathrm{MHz}$ cut off frequency. We determined the average voltage as the $-V_{\mathrm{DC}}$. 


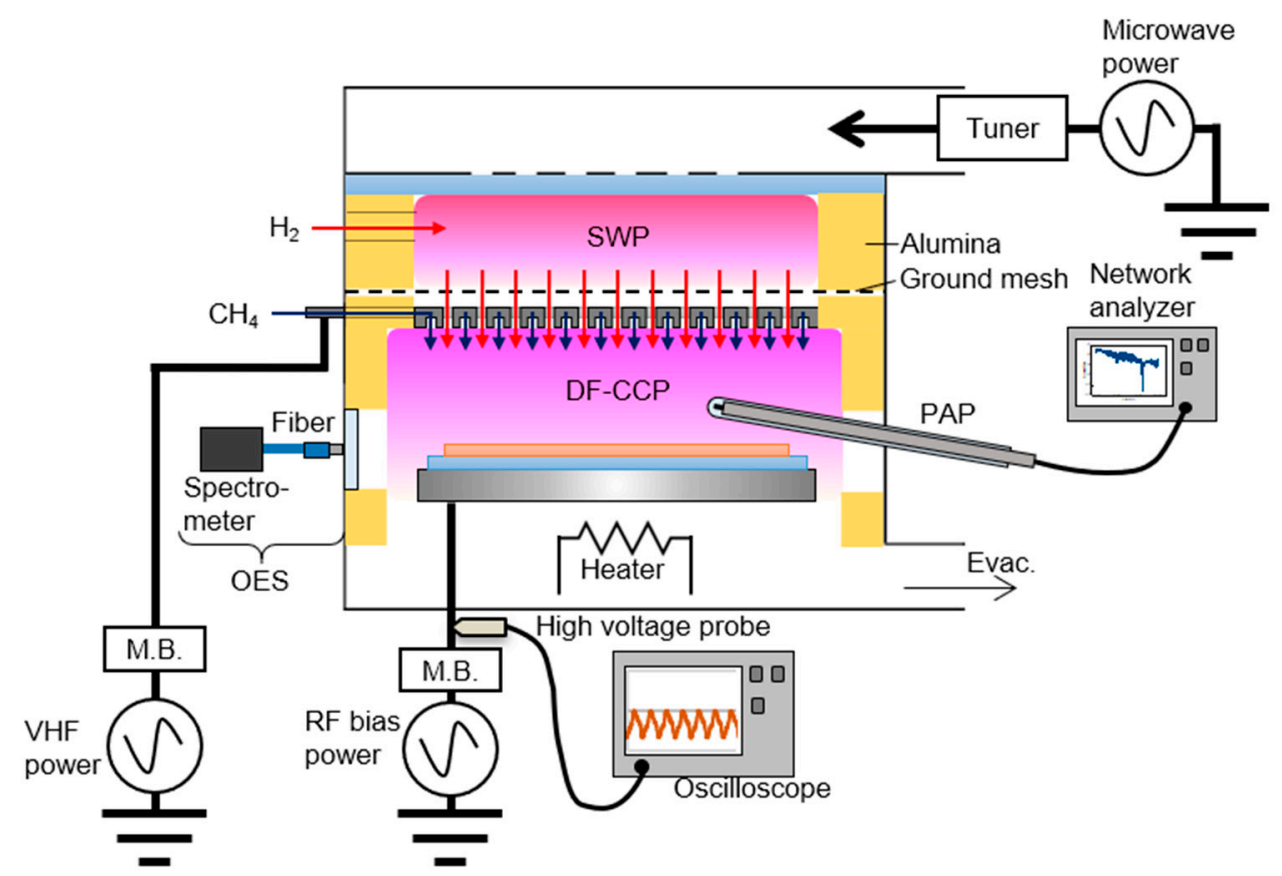

Figure 1. The schematic diagram of radical-injection plasma enhanced chemical vapor deposition (RI-PECVD) system with equipment for optical emission spectroscopy (OES), plasma absorption probe (PAP) method, and radio frequency (RF) bias voltage measurement.

$\mathrm{H}_{2}$ gas was introduced to the SWP region and generated the atomic $\mathrm{H}$. The atomic $\mathrm{H}$ traveled to the lower DF-CCP region through the showerhead. $\mathrm{A} \mathrm{CH}_{4}$ gas was introduced to the DF-CCP chamber to generate hydrocarbon radicals. Flow rates of $500 \mathrm{sccm}$ for $\mathrm{CH}_{4}$ and $250 \mathrm{sccm}$ for $\mathrm{H}_{2}$ were fixed. The ratio of the flow rates, $\mathrm{CH}_{4} / \mathrm{H}_{2}$, significantly influenced the structure of the carbon materials [22-25]. The pressure measured at the DF-CCP region was kept at 12 Pa during all experiments. The deposition time was $20 \mathrm{~min}$.

Synthetic quartz square plates with $15 \mathrm{~mm} \times 15 \mathrm{~mm}$ sizes and thicknesses of $0.5 \mathrm{~mm}$ were used as substrates. The sample stage was heated to $550{ }^{\circ} \mathrm{C}$, which was measured by a thermocouple, and the temperature of the surface of the substrate during deposition was around $400^{\circ} \mathrm{C}$, which was measured by an infrared thermometer (KTL-PRO, LEC company Ltd, Tokyo, Japan). Prior to the deposition process, seasoning of the reaction chamber was conducted for $5 \mathrm{~min}$ using identical conditions to the deposition, but without heating.

The DF-CCP was characterized by the plasma surface waves (SW Probe), previously called the plasma absorption probe (PAP) method, optical emission spectroscopy (OES) [26-30].

The electron density was measured by the PAP. The antenna probe comprising a coaxial cable with a quartz tube was introduced to the DF-CCP region. The probe position was at the center of the electrode gap and near the edge of the stage in the chamber. The antenna length, which was defined as a stripping length of the coaxial cable, i.e., the unshielded region inside the quartz tube, was $6 \mathrm{~mm}$. This length determined the characteristics of the fundamental absorption by the surface wave. The absorption signals were collected by the network analyzer (E5071C, Agilent Technologies, Santa Clara, CA, United States) with a power limiter (11930B, Agilent Technologies, Santa Clara, CA, United States) and a high pass filter (NHP-150+, Mini-Circuits, Brooklyn, NY, United States). The center frequency of the resonant peaks on the measured dispersion curves was determined by fitting Lorentzian functions to the peaks. The electron densities were calculated using the center frequencies $\left(f_{S W}\right)$ of the resonant peaks by the following equation [30].

$$
\mathrm{n}_{\mathrm{e}}\left(\mathrm{cm}^{-3}\right)=1.24\left(1+\varepsilon_{\mathrm{d}}\right) \mathrm{f}_{\mathrm{SW}} \times 10^{10},
$$


where $n_{e}$ is the electron density, $\varepsilon_{d}$ is the dielectric constant of the probe quartz tube (relative permittivity of 3.78), and the unit of $\mathrm{f}_{\mathrm{SW}}$ is $\mathrm{GHz}$.

Optical emission spectra were taken by a spectrometer (HR-2000 CG, Ocean Optics, Largo, FL, United States) using an optical fiber, and the light was collected through a quartz window at the DF-CCP chamber. Comparing hydrogen Balmer line intensity of alpha and beta, the excitation temperature of $\mathrm{H}$ was estimated on the hypothesis of Local Thermodynamic Equilibrium (LTE) by following equation [31].

$$
\mathrm{I}_{\mathrm{H} \alpha} / \mathrm{I}_{\mathrm{H} \beta}=\left[\left(\lambda_{\mathrm{H} \beta} \mathrm{A}_{\mathrm{H} \alpha} \mathrm{g}_{3}\right) /\left(\lambda_{\mathrm{H} \alpha} \mathrm{A}_{\mathrm{H} \beta} \mathrm{g}_{4}\right)\right] \exp \left(-\left(E_{\mathrm{i}}-E_{\mathrm{k}}\right) / \mathrm{k}_{\mathrm{B}} \mathrm{T}_{\mathrm{e}}\right),
$$

where I is the optical emission intensity, $\lambda$ is the wavelength of emission line, $\mathrm{A}$ is transition probability, $\mathrm{g}$ is the degeneracy, $E_{\mathrm{i}}$ and $E_{\mathrm{k}}$ are the energy of state $\mathrm{i}$ and $\mathrm{k}, \mathrm{k}_{\mathrm{B}}$ is Boltzmann constant, $\mathrm{T}_{\mathrm{e}}$ is excitation temperature. The optical emission intensity was calibrated by reference light source (SL1-CAL, Tokyo Instruments, Tokyo, Japan) and subtracted background by the linear baseline.

The ion flux $\left(\Gamma_{\mathrm{i}}\right)$ was determined by the plasma density at the sheath edge $\left(\mathrm{n}_{\mathrm{s}}\right)$ and the Bohm speed $\left(\mathrm{u}_{\mathrm{B}}\right)[32]$.

$$
\Gamma_{\mathrm{i}}=\mathrm{n}_{\mathrm{s}} \mathrm{u}_{\mathrm{B}}=0.61 \mathrm{n}_{\mathrm{e}}\left(\mathrm{eT}_{\mathrm{e}} / \mathrm{M}_{\mathrm{i}}\right)^{1 / 2},
$$

where e is the elementary charge, $\mathrm{M}_{\mathrm{i}}$ is the mass of ion in the plasma. The electron temperature was determined by the $\mathrm{H}$ excitation temperature instead of actual electron temperature, because it is difficult to measure the electron temperature by a Langmuir probe method, due to the deposition to the probe. To determine $\mathrm{M}_{\mathrm{i}}$, the ion composition was measured by positive Secondary Ion Mass Spectroscopy (+SIMS) mode of the quadrupole mass spectrometer (EQP500, Hiden Analytical Ltd., Warrington, United Kingdom) attached at the chamber wall. The extractor voltage was set to $-100 \mathrm{~V}$. Only positive ions were extracted from the plasma and detected. The composition of $\mathrm{M}_{\mathrm{i}}$ was mainly $\mathrm{CH}_{4}{ }^{+}$and $\mathrm{CH}_{3}{ }^{+}$. Therefore, the $\mathrm{M}_{\mathrm{i}}$ was determined to 16 amu for the calculation.

Thicknesses of a-C:H films were measured as a step height between the substrate and the film by a stylus line profiler. And then, the deposition rate was calculated as a value of a thickness divided by the deposition time.

The change of the incorporation of $\mathrm{sp}^{2}-\mathrm{C}$ clusters and $\mathrm{H}$ content of deposited a-C:H films was estimated by visible Raman spectroscopy (inVia Reflex Raman microscope, Renishaw, Gloucestershire, United Kingdom) with excitation of $0.25 \mathrm{~mW}$ of the $532 \mathrm{~nm}$ laser power. An objective lens of 50 magnitudes was used to collect the Raman signals. Raman spectra were obtained by accumulating 20 spectra taken at an integration time of $1 \mathrm{~s}$ for a good signal to noise ratio and to avoid damage by the laser irradiation. The photoluminescence (PL) background of Raman spectra was a linear fit with ranges of $920-970$ and $1800-1950 \mathrm{~cm}^{-1}$. The peak deconvolution of G band and D band was conducted with the Gaussian function. The fitting was performed by the algorism of Levenberg-Marquardt. The evolution of the hydrogen content was estimated using the ratio of PL slope to G-band peak (around $1580 \mathrm{~cm}^{-1}$ ) intensity $\left(\right.$ Slope $\left./ \mathrm{I}_{\mathrm{G}}\right)[10,33,34]$.

To study the density of dangling bonds, electron spin resonance (ESR) measurements were carried out at room temperature using an X-band ESR spectrometer (EMX-plus, BRUKER, Billerica, MA, United States) with $100 \mathrm{kHz}$ modulation of the magnetic field. The density of dangling bonds was estimated using a reference sample of $\mathrm{CuSO}_{4} \cdot 5 \mathrm{H}_{2} \mathrm{O}$ (number of spins; $6.5 \times 10^{18}$ ).

\section{Results}

\subsection{Plasma Characteristics}

To determine the $\Gamma_{E \mathrm{i}}$, the electron density and temperature, and the $-V_{\mathrm{DC}}$ were measured. Figure 1 shows the plasma diagnostics results of $\mathrm{H}_{2} / \mathrm{CH}_{4}$ DF-CCP. Figure 2a shows the electron densities at 20 and $250 \mathrm{~W}$ in the VHF power, respectively, as a function of RF bias power. The electron densities hardly changed regardless of RF bias power. They were around $2.0-2.6 \times 10^{10}$ and $8.8 \times 10^{10} \mathrm{~cm}^{-3}$ 
for $\mathrm{cm}^{-3}$ in the cases with 20 and $250 \mathrm{~W}$ in the VHF power, respectively. RF bias voltage almost did not affect the electron density, because of the electron density increase in proportion to the square of the frequency of the discharge power [35]. The contribution of RF power to the electron density is negligibly small compared with VHF power. Figure $2 \mathrm{~b}$ shows the $\mathrm{H}$ excitation temperature as a function of RF bias power, calculated by the Equation (2). The $\mathrm{H}$ excitation temperature was almost constant to be about $2 \mathrm{eV}$ regardless of both VHF and RF bias powers. The electron temperature usually depends on the process pressure, because the acceleration of electrons depends on the mean free path. In the current study, the pressure was kept at $12 \mathrm{~Pa}$. So that, the electron temperature was almost not changed. Figure $2 \mathrm{c}$ shows the dependence of the $\left|-V_{\mathrm{DC}}\right|$ on the RF bias power. The $\left|-V_{\mathrm{DC}}\right|$ increased almost linearly with increasing the RF bias power. Figure $2 \mathrm{~d}$ shows the $\Gamma_{\mathrm{i}}$ values calculated using Equation (3) as a function of $\left|-V_{\mathrm{DC}}\right|$. They hardly changed regardless of $\left|-V_{\mathrm{DC}}\right|$ to be $4.0-5.4 \times 10^{15}$ and $1.8 \times 10^{16} \mathrm{~cm}^{-2} \mathrm{~s}^{-1}$ in the cases with 20 and $250 \mathrm{~W}$ in VHF power, respectively. This means the $\Gamma_{\mathrm{i}}$ depends on the VHF power rather than the $\left|-V_{\mathrm{DC}}\right|$, because the $\Gamma_{\mathrm{i}}$ depends on the electron density via the VHF power, in contrast, I- $V_{\mathrm{DC}} \mid$ depends on the RF bias power.

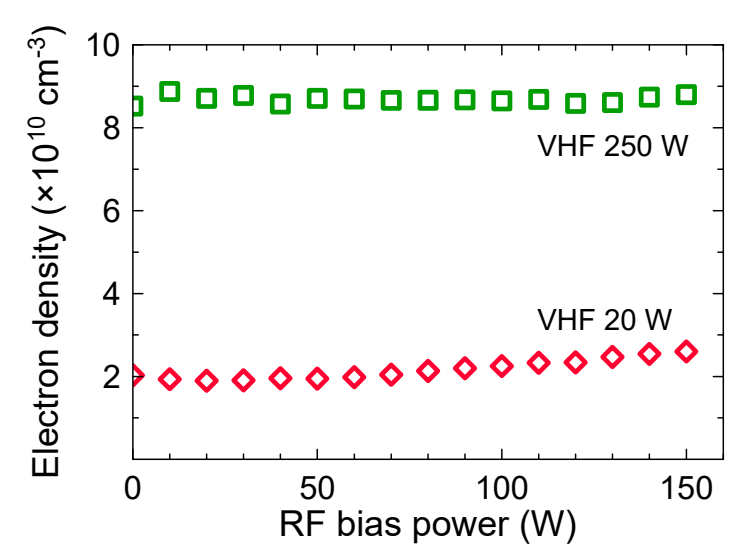

(a)

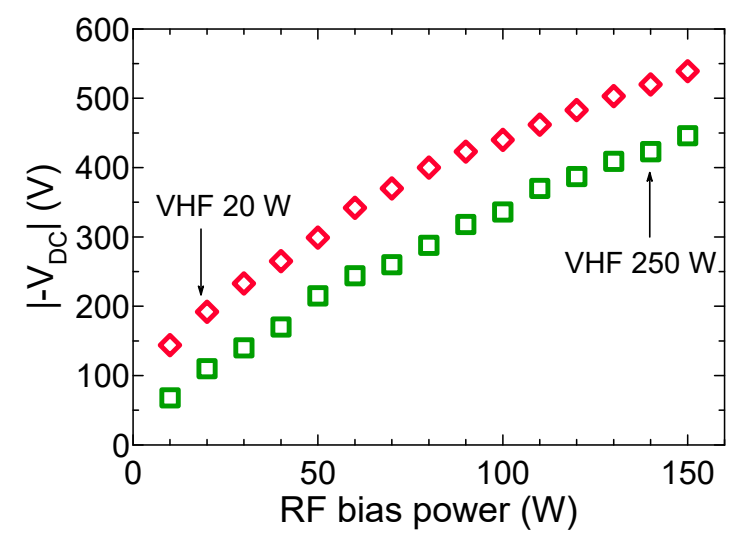

(c)

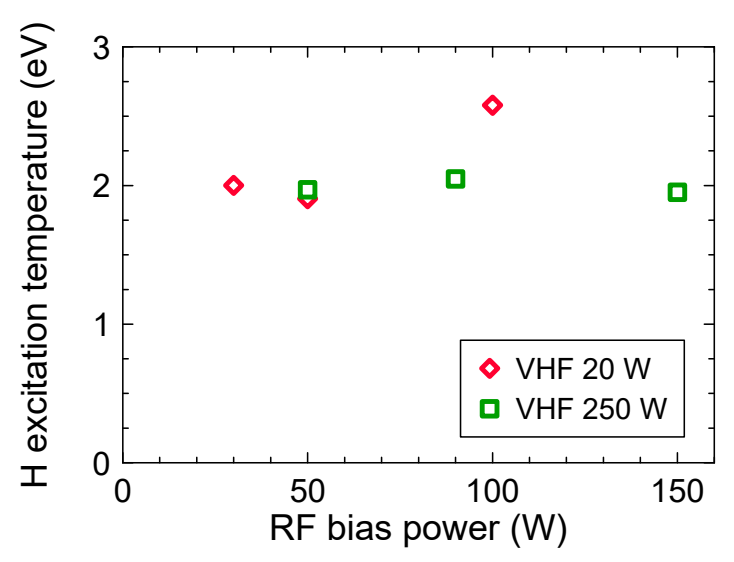

(b)

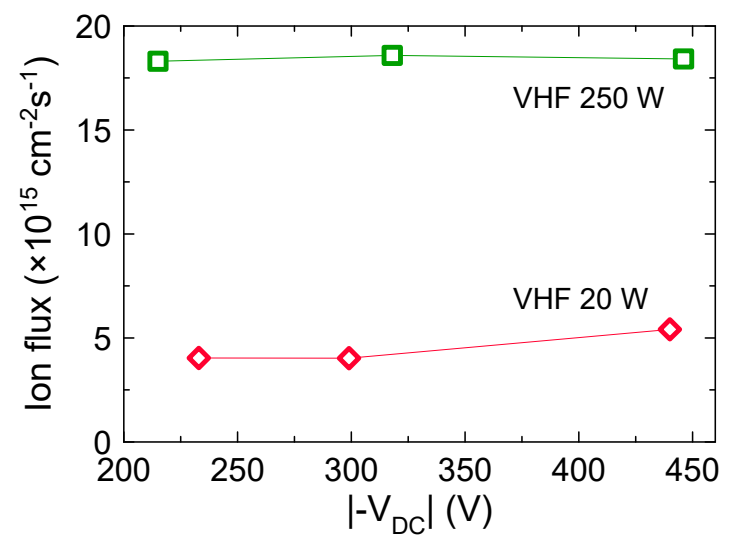

(d)

Figure 2. (a) Electron densities, (b) H excitation temperatures, and (c) magnitudes of negative self-bias voltages $\left(\left|-V_{\mathrm{DC}}\right|\right)$ as a function of RF bias power, and (d) ion fluxes as a function of $\left|-V_{\mathrm{DC}}\right|$. Diamonds $(\diamond)$ and squares $(\square)$ correspond to 20 and $250 \mathrm{~W}$ in very high frequency (VHF) power, respectively.

Figure 3 shows the $\Gamma_{E \mathrm{i}}$ values calculated from $\left|-V_{\mathrm{DC}}\right| \times \Gamma_{\mathrm{i}}$ at 20 and $250 \mathrm{~W}$ in VHF power, respectively, as a function of the RF bias power. $\Gamma_{E \mathrm{i}}$ increased from $0.9 \times 10^{18}$ to $2.4 \times 10^{18} \mathrm{Vcm}^{-2} \mathrm{~s}^{-1}$ and from $3.9 \times 10^{18}$ to $8.2 \times 10^{18} \mathrm{Vcm}^{-2} \mathrm{~s}^{-1}$ for 20 and $250 \mathrm{~W}$ in VHF power, respectively. This suggested that the combination of VHF power and RF bias power can precisely control the plasma properties. Based on plasma characteristics, effects of $\Gamma_{E \mathrm{i}}$ on the deposition rate, the incorporation of $\mathrm{sp}^{2}-\mathrm{C}$ clusters, the $\mathrm{H}$ content, and the density of dangling bonds are discussed in Sections 3.2 and 3.3. 


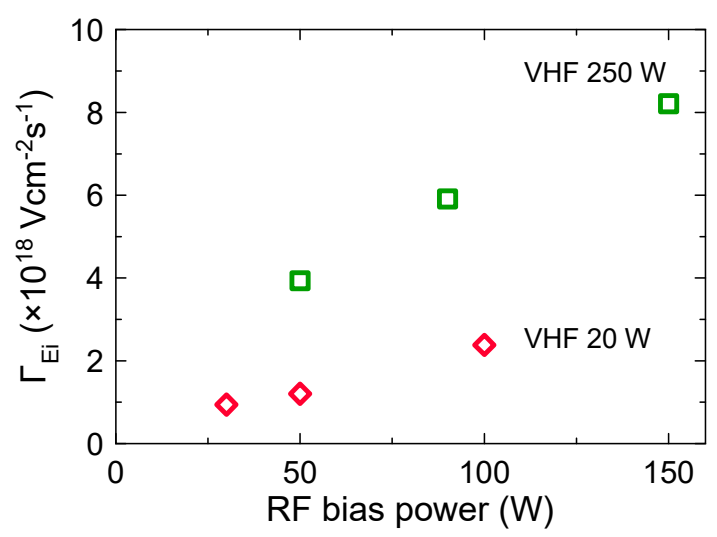

Figure 3. Ion bombardment energy fluxes $\Gamma_{E \mathrm{i}}$ as a function of RF bias powers. Diamonds $(\diamond)$ and squares $(\square)$ correspond to 20 and $250 \mathrm{~W}$ in VHF power, respectively.

\subsection{Effects of Ion Bombardment Energy Flux on the Deposition Rate}

Figure 4a shows the deposition rate of a-C:H films as a function of $\left|-V_{\mathrm{DC}}\right|$. In both cases with 20 and $250 \mathrm{~W}$ in VHF power, they almost proportionally decreased with increasing $\left|-V_{\mathrm{DC}}\right|$ in the same manner. However, values of Slope $/ \mathrm{I}_{\mathrm{G}}$ in VHF $20 \mathrm{~W}$ are higher than that in VHF $250 \mathrm{~W}$. By plotting the deposition rate as a function of $\Gamma_{E \mathrm{i}}$, plots are almost on one line, as shown in Figure $4 \mathrm{~b}$. It is assumed that the surface dangling bonds are generated by ion bombardment depending on not only its energy, but also its flux, and then the sticking of radicals are enhanced. This result indicates that the deposition rate depends on $\Gamma_{E \mathrm{i}}$ and $\Gamma_{E \mathrm{i}}$ should be the candidate for the factor of the deposition mechanism of a-C:H in PECVD.

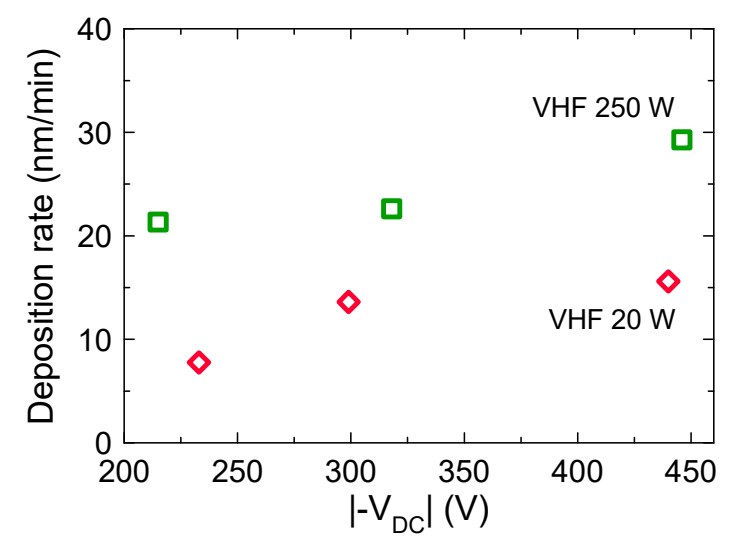

(a)

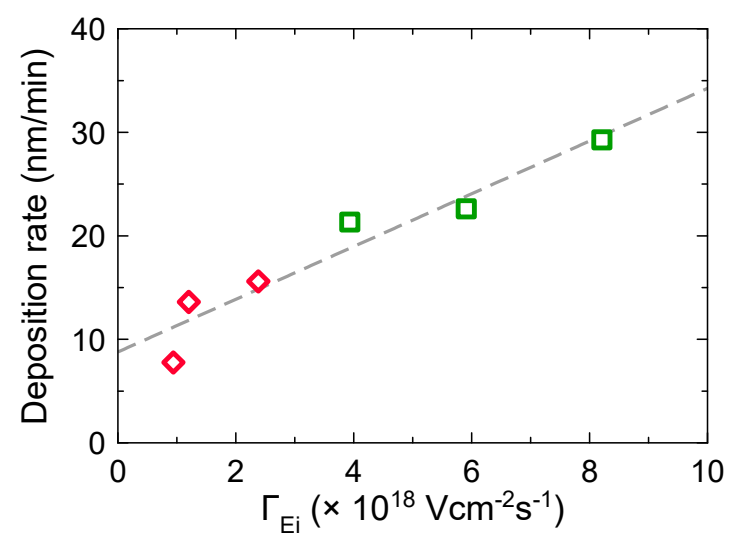

(b)

Figure 4. Deposition rate as a function of (a) magnitudes of negative self-bias voltages $\left(\left|-V_{\mathrm{DC}}\right|\right)$ and (b) ion bombardment energy fluxes. Diamonds $(\diamond)$ and squares $(\square)$ correspond to 20 and $250 \mathrm{~W}$ in VHF power, respectively.

3.3. Effects of Ion Bombardment Energy Flux on the Incorpolation of sp ${ }^{2}-C$ Clusters, the Slope/I $\mathrm{I}_{G}$ and the Density of Dangling Bonds

Figure 5 shows the Raman spectra of as-deposited a-C:H films deposited at different VHF and RF bias powers. G- and D- band peaks, which corresponded to the $\mathrm{sp}^{2}$ bonded carbon and the edge of the six-membered ring structure respectively, became sharper as the RF bias power increased. In addition, their widths at $20 \mathrm{~W}$ were larger than those at $250 \mathrm{~W}$. This can be interpreted that thermal spike and relaxation occur with increasing the VHF and RF bias powers. 


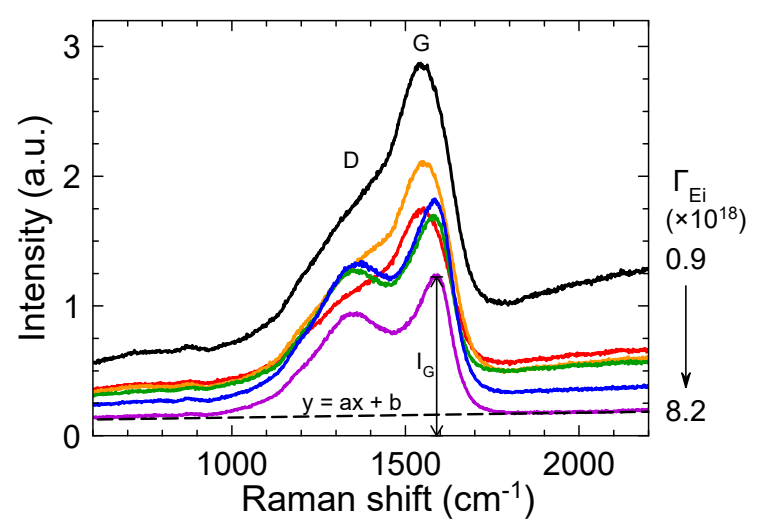

Figure 5. The Raman spectra of as-deposited a-C:H films. Top 3 spectra are a-C:H films deposited at $20 \mathrm{~W}$ in VHF power (black, orange, and red lines) and bottom 3 spectra are a-C:H films deposited at $250 \mathrm{~W}$ in VHF power (green, blue, and purple lines). The ion bombardment energy flux $\Gamma_{E \mathrm{i}}$ are shown at the right and its value increase from top to bottom.

Figure 6 shows the results of peak deconvolutions of Raman spectra of a-C:H films. Figure $6 \mathrm{a}$ shows the $\left|-V_{\mathrm{DC}}\right|$ dependence of $\mathrm{G}$ band position ( $\mathrm{G}$ position), $\mathrm{FWHM}$ of $\mathrm{G}$ band $\left(\mathrm{FWHM}_{\mathrm{G}}\right)$, and the intensity ratio of $\mathrm{D}$ band to $\mathrm{G}$ band $\left(\mathrm{I}_{\mathrm{D}} / \mathrm{I}_{\mathrm{G}}\right)$. With increasing $\left|-V_{\mathrm{DC}}\right|$, the $\mathrm{G}$ position and $\mathrm{I}_{\mathrm{D}} / \mathrm{I}_{\mathrm{G}}$ slightly increased, and the $\mathrm{FWHM}_{\mathrm{G}}$ slightly decreased. This trend implies that the ion bombardment enhances the incorporation of $\mathrm{sp}^{2}-\mathrm{C}$ clusters by thermal spike and relaxation process. However, the difference between 20 and $250 \mathrm{~W}$ in VHF power is larger than the changes of these values by $\left|-V_{\mathrm{DC}}\right|$. Considering $\Gamma_{E i}$, the $G$ position, the $I_{D} / I_{G}$, and the $F_{W H M}$ can be described as one trend. Figure $6 \mathrm{~b}$ shows the $\mathrm{G}$ position, the $\mathrm{I}_{\mathrm{D}} / \mathrm{I}_{\mathrm{G}}$, and the $\mathrm{FWHM}_{\mathrm{G}}$ as functions of $\Gamma_{E \mathrm{i}}$. With increasing $\Gamma_{E \mathrm{i}}$ from $0.9 \times 10^{18}$ up to $4.0 \times 10^{18} \mathrm{Vcm}^{-2} \mathrm{~s}^{-1}$, these 3 values linearly changed. Then, from $4.0 \times 10^{18} \mathrm{Vcm}^{-2} \mathrm{~s}^{-1}$, the slope of changes decreased. Merlen et al. and Rose et al. reported that the plot of $G$ position versus FWHM $_{\mathrm{G}}$ for visible Raman spectra of a-C $[33,36]$. They showed that the increase in $\mathrm{G}$ position and decrease in $\mathrm{FWHM}_{\mathrm{G}}$ indicates the incorporation of $\mathrm{sp}^{2}-\mathrm{C}$ clusters and the change of structures to nanocrystalline graphite (nc-G). Therefore, the change of $\mathrm{G}$ position and $\mathrm{FWHM}_{\mathrm{G}}$ in the current study can be interpreted that the a-C:H films become nc- $\mathrm{G}$ by the ion bombardment energy flux. The increase in $\mathrm{I}_{\mathrm{D}} / \mathrm{I}_{\mathrm{G}}$ indicates that the increase in the crystallite size of $\mathrm{sp}^{2}-\mathrm{C}$ clusters [37]. So that, the increase of the ion bombardment energy flux enhanced the incorporation of $\mathrm{sp}^{2}-\mathrm{C}$ clusters.

On the other hand, the PL background was decreased with increasing the VHF and RF bias power, as shown in Figure 5. In addition, the PL backgrounds at $20 \mathrm{~W}$ was larger than those at $250 \mathrm{~W}$. In general, the $\mathrm{H}$ containing a-C:H films, usually deposited by the PECVD, shows the high intensity of the background signal, because the recombination of excited electrons depends on the $\mathrm{H}$ content. Therefore, this PL background is often used to estimate the H content [10,33,38-40]. However, it should be noted that the density of dangling bonds in the a-C:H film can also increase the PL background as Rose et al. reported [33]. The intensity ratio of the PL background to G-band peak (Slope/ $\mathrm{I}_{\mathrm{G}}$ ), increased with increasing the post-annealing temperature, because of the passivation of the dangling bonds [33]. According to the molecular dynamic (MD) simulation, an increase of the number of $C=C$ double bonds without changing the number of $\mathrm{H}$ atoms and $\mathrm{C}-\mathrm{H}$ bonds suggested that the dangling bonds vanish as results of $\mathrm{sp}^{2}$ clustering and $\mathrm{C}$ reorganization. Conversely, this result also suggested that, if the density of dangling bonds hardly changed or decreased depending on any process conditions, an increase in the Slope $/ \mathrm{I}_{\mathrm{G}}$ indicates the increase of the $\mathrm{H}$ content. Figure 7 a shows the Slope $/ \mathrm{I}_{\mathrm{G}}$ values as a function of $\left|-V_{\mathrm{DC}}\right|$. As shown in the figure, in both the cases with 20 and $250 \mathrm{~W}$ in VHF power, they almost proportionally decreased with increasing $\left|-V_{\mathrm{DC}}\right|$ in the same manner. However, values of Slope $/ \mathrm{I}_{\mathrm{G}}$ at VHF $20 \mathrm{~W}$ are higher than those at VHF $250 \mathrm{~W}$. Figure $7 \mathrm{~b}$ shows the Slope $/ \mathrm{I}_{\mathrm{G}}$ values as a function of $\Gamma_{E \mathrm{i}}$. They almost proportionally decreased with increasing $\Gamma_{E \mathrm{i}}$ in the one line. These results suggested that the Slope $/ \mathrm{I}_{\mathrm{G}}$ values depend on not only the $E_{\mathrm{i}}$, but also the $\Gamma_{E \mathrm{i}}$. 


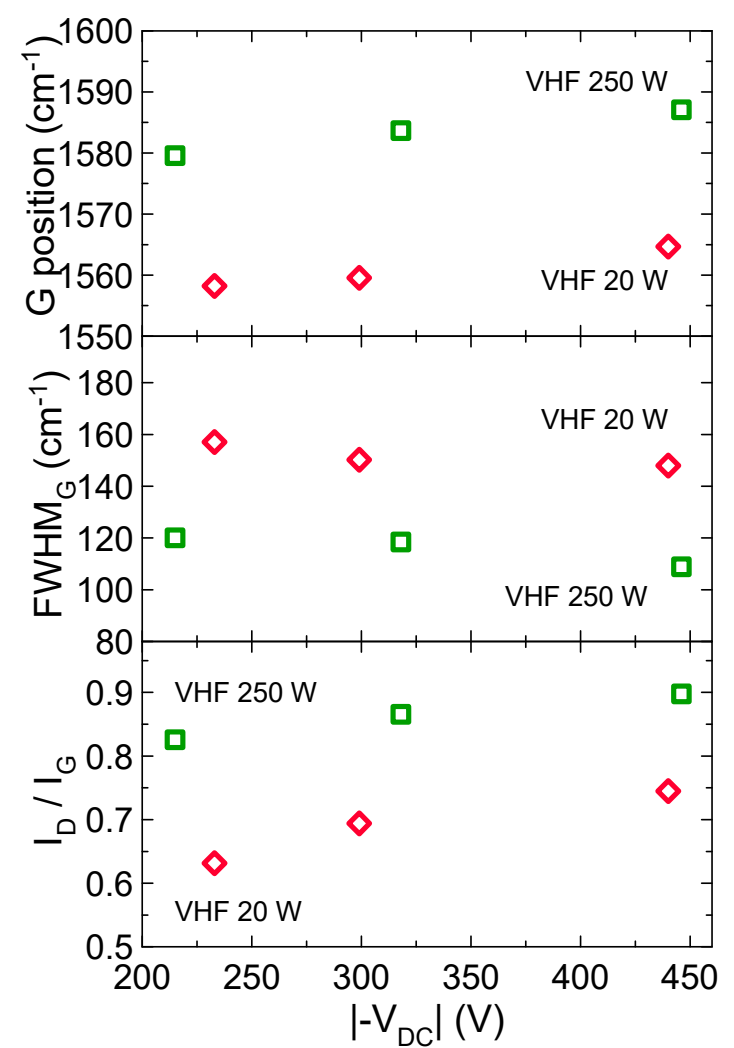

(a)

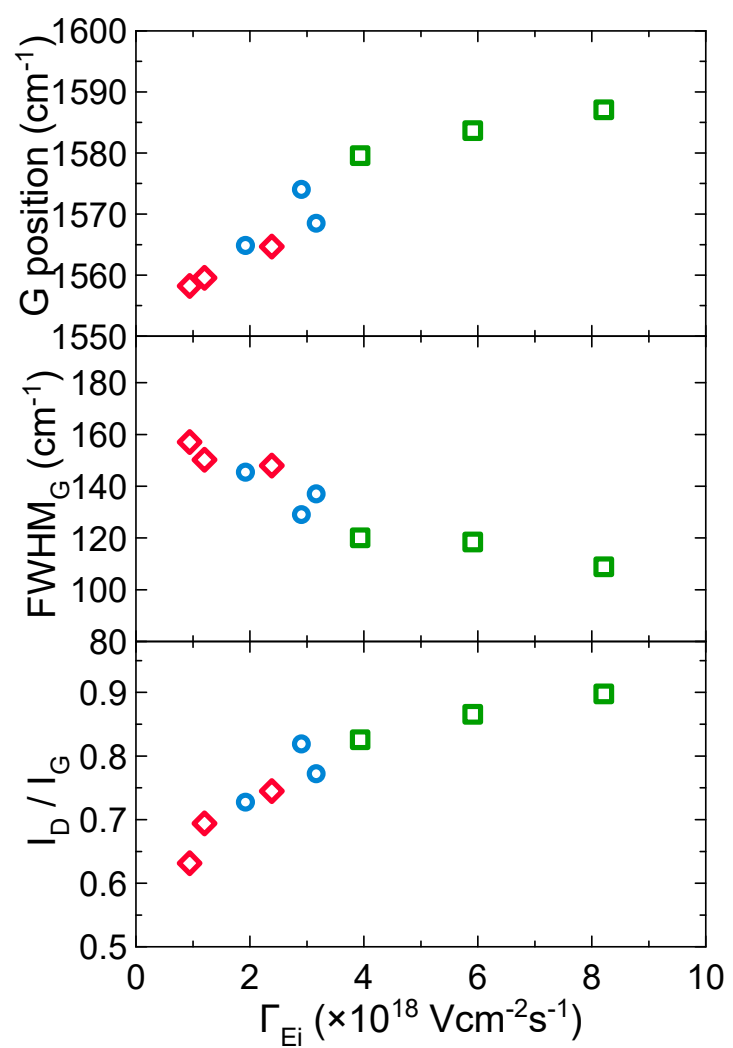

(b)

Figure 6. (a) The magnitude of the negative self-bias voltage $\left|-V_{\mathrm{DC}}\right|$ and (b) the ion bombardment energy flux $\Gamma_{E \mathrm{i}}$ dependences of $\mathrm{G}$ band position ( $\mathrm{G}$ position), FWHM of $\mathrm{G}$ band $\left(\mathrm{FWHM}_{\mathrm{G}}\right.$ ), and the intensity ratio of $\mathrm{D}$ band to $\mathrm{G}$ band $\left(\mathrm{I}_{\mathrm{D}} / \mathrm{I}_{\mathrm{G}}\right)$. Diamonds $(\diamond)$ correspond to $20 \mathrm{~W}$ in VHF power, squares $(\square)$ correspond to $250 \mathrm{~W}$ in VHF power, and circles $(\bigcirc)$ correspond to 50, 100, and $200 \mathrm{~W}$ in VHF power with $50 \mathrm{~W}$ of RF bias power.

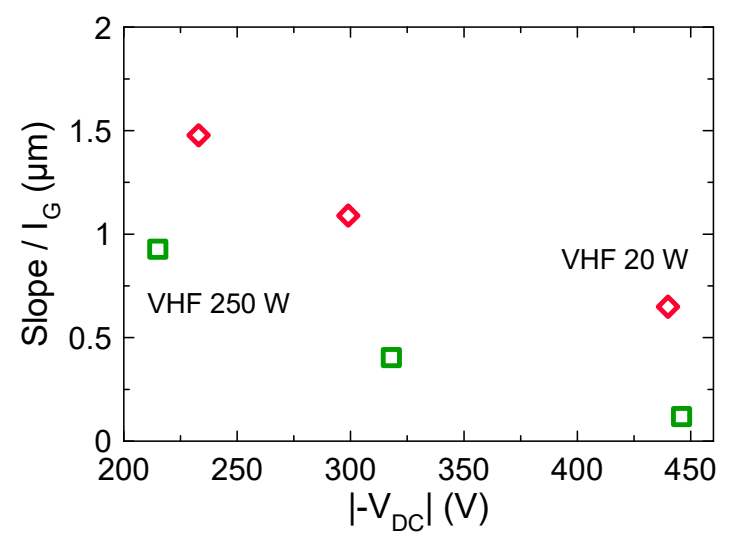

(a)

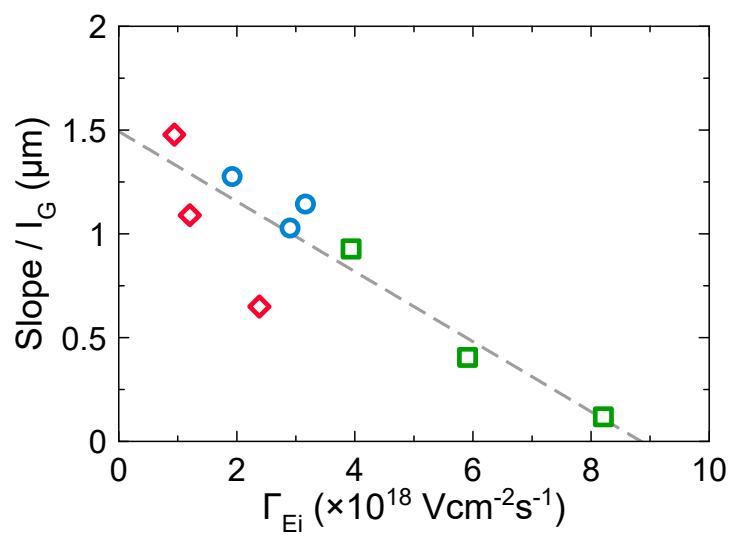

(b)

Figure 7. The Slope $/ \mathrm{I}_{\mathrm{G}}$ as functions of (a) the magnitude of the negative self-bias voltage $\left|-V_{\mathrm{DC}}\right|$ and (b) the ion bombardment energy flux $\Gamma_{E \mathrm{i}}$. Diamonds $(\diamond)$ correspond to $20 \mathrm{~W}$ in VHF power, squares $(\square)$ correspond to $250 \mathrm{~W}$ in VHF power, and circles $(\bigcirc)$ correspond to 50, 100, and $200 \mathrm{~W}$ in VHF power with $50 \mathrm{~W}$ of RF bias power.

Figure 8 shows the density of dangling bonds of the a-C:H films. With increasing the $\Gamma_{E \mathrm{i}}$, the density of dangling bonds decreased in the same manner in both the cases with 20 and $250 \mathrm{~W}$ in 
VHF power, as well as the Slope $/ \mathrm{I}_{\mathrm{G}}$ values. This result indicated that the ion bombardment energy flux effectively reduced the dangling bonds of a-C:H films.

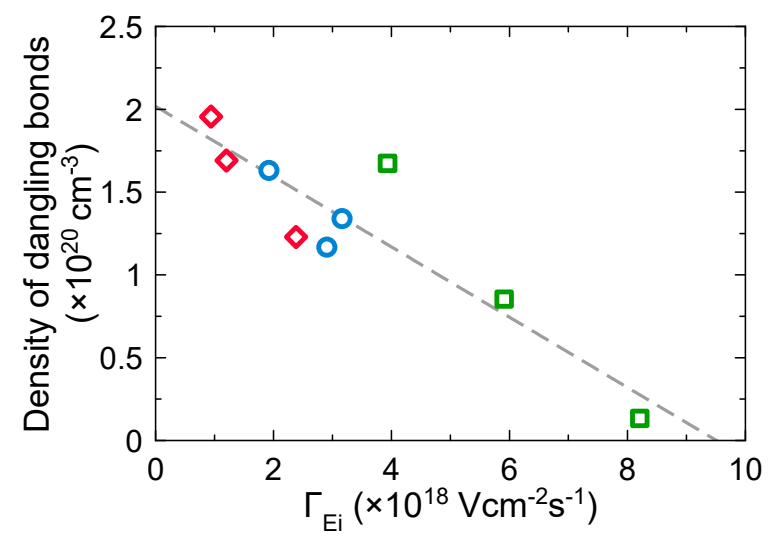

Figure 8. The dangling bonds density as a function of the ion bombardment flux. Diamonds $(\diamond)$ correspond to $20 \mathrm{~W}$ in VHF power, squares $(\square)$ correspond to $250 \mathrm{~W}$ in VHF power, and circles $(\bigcirc)$ correspond to 50, 100, and $200 \mathrm{~W}$ in VHF power with $50 \mathrm{~W}$ of RF bias power.

\section{Discussion}

It was found in this study that both the Slope $/ \mathrm{I}_{\mathrm{G}}$ and the density of dangling bonds decreased with increasing the $\Gamma_{E \mathrm{i}}$. The passivation of dangling bonds could enhance the PL background of $\mathrm{a}-\mathrm{C}: \mathrm{H}$ films. Therefore, the Slope $/ \mathrm{I}_{G}$ with the $\Gamma_{E \mathrm{i}}$ found in this study indicates the decrease in $\mathrm{H}$ content rather than the increase in the density of dangling bonds. The passivation of dangling bonds with the desorption of $\mathrm{H}$ by the ion bombardment can be assumed as the following mechanism. The displacement of $\mathrm{H}$ atoms from the $\mathrm{C}-\mathrm{H}$ bonding preferentially occurs than that of $\mathrm{C}$ atoms, because of the lower displacement threshold energy of $\mathrm{H}$ atom than that of $\mathrm{C}$ [15]. This displacement rate of $\mathrm{H}$ depends on the $E_{\mathrm{i}}$. The penetration depth of ion become the deeper and the collisions in the film increase with increasing the $E_{\mathrm{i}}$. Furthermore, a multiple collision in the films results in much displacement of $\mathrm{H}$ atom from the $\mathrm{C}-\mathrm{H}$ bonding. Therefore, with increasing the $\Gamma_{E \mathrm{i}}$, the flux of $\mathrm{H}$ subtraction from the $\mathrm{C}-\mathrm{H}$ bonding increases, because of the energy transfer from the ions to the $\mathrm{C}-\mathrm{H}$ bonds by an increase of collision frequency. The $\mathrm{H}$ abstraction induces to form the carbon-carbon continuous network with the neighboring $\mathrm{C}$ atoms which have dangling bonds. This conversion contributes to the decrease in the density of dangling bonds with decreasing the $\mathrm{H}$ content. Moreover, from the Raman analysis result, it can be assumed that the formation of carbon-carbon continuous network originated from the incorporation of $\mathrm{sp}^{2}-\mathrm{C}$ clusters, due to the relaxation process proposed in the subplantation model. Therefore, the $\Gamma_{E \mathrm{i}}$ proposed in the current study is crucial to consider for controlling the $\mathrm{H}$ content and the carbon-carbon continuous network of $\mathrm{sp}^{2}$-C clusters in a-C:H films deposited by the PECVD.

\section{Conclusions}

The effects of ion bombardment energy flux $\left(\Gamma_{E \mathrm{i}}\right)$ on the PL background of Raman spectra and the dangling bond density were investigated. The $\Gamma_{E \mathrm{i}}$ was estimated from the plasma density at the sheath of plasma and Bohm speed based on the measurements of electron density, $\mathrm{H}$ excitation temperature, and negative self-bias voltage. According to the PAP, the electron densities only depended on the VHF power. They were around 2.0-2.6 $\times 10^{10}$ and $8.8 \times 10^{10} \mathrm{~cm}^{-3}$ for the 20 and $250 \mathrm{~W}$ in VHF power, respectively. The $\mathrm{H}$ excitation temperature was estimated $2 \mathrm{eV}$ from the intensity ratio of $\mathrm{H}_{\alpha}$ and $\mathrm{H}_{\beta}$ of the optical emission. From the electron density at the sheath edge and the Bohm speed of $\mathrm{CH}_{4}$ ion, the ion fluxes were calculated to be $4.0-5.4 \times 10^{15}$ and $1.8 \times 10^{16} \mathrm{Vcm}^{-2} \mathrm{~s}^{-1}$ in the cases with 20 and $250 \mathrm{~W}$ in VHF power, respectively. The negative self-bias voltage was controlled by the RF bias power. Thus, the $\Gamma_{E \mathrm{i}}$ was controlled by both the VHF power and the RF bias power. The deposition 
rate was increased with increasing the $\Gamma_{E \mathrm{i}}$, due to the formation of surface dangling bonds by the $\mathrm{H}$ desorption. The PL background of Raman spectra and the density of dangling bonds indicated that the decrease of $\mathrm{H}$ content with increasing the $\Gamma_{E \mathrm{i}}$. And the density of dangling bonds and Raman analysis results of $\mathrm{G}$ position, $\mathrm{FWHM}_{\mathrm{G}}$, and $\mathrm{I}_{\mathrm{D}} / \mathrm{I}_{\mathrm{G}}$ indicated that the carbon-carbon continuous network of $\mathrm{sp}^{2}-\mathrm{C}$ clusters was induced by an increase of the $\Gamma_{E \mathrm{i}}$. Therefore, the $\Gamma_{E \mathrm{i}}$ proposed in this study is one of the crucial factors in the $\mathrm{H}$ desorption mechanism and makes the precise control of a-C:H films in the PECVD possible.

Author Contributions: H.S. conceived, designed, and performed the experiments, and analyzed the data, and wrote the paper. H.K., T.T., K.I., and M.H. provided advice and helped writing the paper.

Funding: This research received no external funding.

Acknowledgments: The authors would like to thank Koji Yamakawa for technical support.

Conflicts of Interest: The authors declare no conflict of interest.

\section{References}

1. Ray, S.C.; Mukherjee, D.; Sarma, S.; Bhattacharya, G.; Mathur, A.; Roy, S.S.; McLaughlin, J.A. Functional diamond like carbon (DLC) coatings on polymer for improved gas barrier performance. Diam. Relat. Mater. 2017, 80, 59-63. [CrossRef]

2. Koós, M.; Füle, M.; Veres, M.; Tóth, S.; Pócsik, I. Multi-band structure of amorphous carbon luminescence. Diam. Relat. Mater. 2002, 11, 1115-1118. [CrossRef]

3. Gerstner, E.G.; Mckenzie, D.R. Fabrication and characterization of novel electronic devices using tetrahedral amorphous carbon. Diam. Relat. Mater. 2006, 7, 1172-1177. [CrossRef]

4. Adhikari, S.; Adhikary, S.; Omer, A.M.M.; Rusop, M.; Uchida, H.; Soga, T.; Umeno, M. Optical and structural properties of amorphous carbon thin films deposited by microwave surface-wave plasma CVD. Diam. Relat. Mater. 2006, 15, 188-192. [CrossRef]

5. Andujar, J.L.; Polo, M.C.; Esteve, J.; Robertson, J.; Milne, W.I.; Martínez, E. Study of the mechanical properties of tetrahedral amorphous carbon films by nanoindentation and nanowear measurements. Diam. Relat. Mater. 2001, 10, 145-152. [CrossRef]

6. Tiainen, V. Amorphous carbon as a bio-mechanical coating-Mechanical properties and biological applications. Diam. Relat. Mater. 2001, 10, 153-160. [CrossRef]

7. Kanda, K.; Fukuda, K.; Kidena, K.; Imai, R.; Niibe, M.; Fujimoto, S.; Yokota, K.; Tagawa, M. Hyperthermal atomic oxygen beam irradiation effect on the Ti-containing DLC film. Diam. Relat. Mater. 2014, 41, 49-52. [CrossRef]

8. Wazumi, K.; Koga, Y.; Tanaka, A. Tribological properties of a-C:H films on Si substrate prepared by plasma CVD in pulse-biased process. Diam. Relat. Mater. 2003, 12, 1018-1023. [CrossRef]

9. Ohgoe, Y.; Hirakuri, K.K.; Saitoh, H.; Nakahigashi, T.; Ohtake, N.; Hirata, A.; Kanda, K.; Hiratsuka, M.; Fukui, Y. Classification of DLC films in terms of biological response. Surf. Coat. Technol. 2012, 207, 350-354. [CrossRef]

10. Marchon, B.; Gui, J.; Grannen, K.; Rauch, G.C.; Ager, J.W.; Silva, S.R.P.; Robertson, J. Photoluminescence and Raman spectroscopy in hydrogenated carbon films. IEEE Trans. Magn. 1997, 33, 3148-3150. [CrossRef]

11. Robertson, J. Plasma Deposition of Diamond-Like Carbon. Jpn. J. Appl. Phys. 2011, 50, 01AF01. [CrossRef]

12. Lifshitz, Y.; Kasi, S.R.; Rabalais, J.W.; Eckstein, W. Subplantation model for film growth from hyperthermal species. Phys. Rev. B 1990, 41, 10468-10480. [CrossRef]

13. Robertson, J. Deposition mechanisms for promoting sp3 bonding in diamond-like carbon. Diam. Relat. Mater. 1993, 2, 984-989. [CrossRef]

14. Möller, W. Modelling and computer simulation of ion-beam- and plasma-assisted film growth. Thin Solid Films 1993, 228, 319-325. [CrossRef]

15. Robertson, J. The deposition mechanism of diamond-like a-C and a-C: H. Diam. Relat. Mater. 1994, 3, 361-368. [CrossRef]

16. Davis, C.A. A simple model for the formation of compressive stress in thin films by ion bombardment. Thin Solid Films 1993, 226, 30-34. [CrossRef] 
17. Miyagawa, Y.; Nakadate, H.; Ikeyama, M.; Nakao, S.; Miyagawa, S. Dynamic MC simulation for a-C:H deposition in methane plasma based on subplantation model. Diam. Relat. Mater. 2003, 12, 927-930. [CrossRef]

18. Godet, C.; Conway, N.M.J.; Bourée, J.E.; Bouamra, K.; Grosman, A.; Ortega, C. Structural and electronic properties of electron cyclotron resonance plasma deposited hydrogenated amorphous carbon and carbon nitride films. J. Appl. Phys. 2002, 91, 4154. [CrossRef]

19. Oda, A.; Kousaka, H. Numerical Analysis of Substrate-Incident Carbon Flux in Low-Pressure Radio-Frequency CH 4 Plasmas for Deposition of Diamond-Like Carbon Films. Electron. Commun. Jpn. 2015, 98, 31-39. [CrossRef]

20. Sugiura, H.; Jia, L.; Kondo, H.; Ishikawa, K.; Tsutsumi, T.; Hayashi, T.; Takeda, K.; Sekine, M.; Hori, M. Effects of gas residence time of $\mathrm{CH}_{4} / \mathrm{H}_{2}$ on $\mathrm{sp}^{2}$ fraction of amorphous carbon films and dissociated methyl density during radical-injection plasma-enhanced chemical vapor deposition. Jpn. J. Appl. Phys. 2018, 57, 06JE03. [CrossRef]

21. Jia, L.; Sugiura, H.; Kondo, H.; Takeda, K.; Ishikawa, K.; Oda, O.; Sekine, M.; Hiramatsu, M.; Hori, M. Effects of Radical Species on Structural and Electronic Properties of Amorphous Carbon Films Deposited by Radical-Injection Plasma-Enhanced Chemical Vapor Deposition. Plasma Process. Polym. 2016, 13, 730-736. [CrossRef]

22. Kondo, S.; Hori, M.; Yamakawa, K.; Den, S.; Kano, H.; Hiramatsu, M. Highly reliable growth process of carbon nanowalls using radical injection plasma-enhanced chemical vapor deposition. J. Vac. Sci. Technol. B Microelectron. Nanom. Struct. 2008, 26, 1294. [CrossRef]

23. Hiramatsu, M.; Kondo, H.; Hori, M. New Progress on Graphene Research; IntechOpen: London, UK, 2013.

24. Mankelevich, Y.A.; May, P.W. New insights into the mechanism of CVD diamond growth: Single crystal diamond in MW PECVD reactors. Diam. Relat. Mater. 2008, 17, 1021-1028. [CrossRef]

25. Toyota, H.; Nomura, S.; Mukasa, S.; Yamashita, H.; Shimo, T.; Okuda, S. A consideration of ternary C-H-O diagram for diamond deposition using microwave in-liquid and gas phase plasma. Diam. Relat. Mater. 2011, 20, 1255-1258. [CrossRef]

26. Ueyama, T.; Fukunaga, Y.; Tsutsumi, T.; Takeda, K.; Kondo, H.; Ishikawa, K.; Sekine, M.; Iwata, M.; Ohya, Y.; Sugai, H.; et al. Electron behaviors in afterglow of synchronized dc-imposed pulsed fluorocarbon-based plasmas. Jpn. J. Appl. Phys. 2017, 56, 06HC03. [CrossRef]

27. Ohya, Y.; Ishikawa, K.; Komuro, T.; Yamaguchi, T.; Takeda, K.; Kondo, H.; Sekine, M.; Hori, M. Spatial profiles of interelectrode electron density in direct current superposed dual-frequency capacitively coupled plasmas. J. Phys. D. Appl. Phys. 2017, 50, 155201. [CrossRef]

28. Ohya, Y.; Iwata, M.; Ishikawa, K.; Sekine, M.; Hori, M.; Sugai, H. Rapid electron density decay observed by surface-wave probe in afterglow of pulsed fluorocarbon-based plasma. Jpn. J. Appl. Phys. 2016, 55, 080309. [CrossRef]

29. Yamaguchi, T.; Komuro, T.; Koshimizu, C.; Takashima, S.; Takeda, K.; Kondo, H.; Ishikawa, K.; Sekine, M.; Hori, M. Direct current superposed dual-frequency capacitively coupled plasmas in selective etching of SiOCH over SiC. J. Phys. D. Appl. Phys. 2012, 45, 025203. [CrossRef]

30. Kokura, H.; Nakamura, K.; Ghanashev, I.P.; Sugai, H. Plasma Absorption Probe for Measuring Electron Density in an Environment Soiled with Processing Plasmas. Jpn. J. Appl. Phys. 1999, 38, 5262-5266. [CrossRef]

31. Park, C. Hydrogen line ratios as electron temperature indicators in nonequilibrium plasmas. J. Quant. Spectrosc. Radiat. Transf. 1972, 12, 323-370. [CrossRef]

32. Lieberman, M.A.; Lichtenberg, A.J. Principles of Plasma Discharges and Materials Processing; Wiley-Interscience: Hoboken, NJ, USA, 2005.

33. Rose, F.; Wang, N.; Smith, R.; Xiao, Q.-F.; Inaba, H.; Matsumura, T.; Saito, Y.; Matsumoto, H.; Dai, Q.; Marchon, B.; et al. Complete characterization by Raman spectroscopy of the structural properties of thin hydrogenated diamond-like carbon films exposed to rapid thermal annealing. J. Appl. Phys. 2014, 116, 123516. [CrossRef]

34. Buijnsters, J.G.; Gago, R.; Jiménez, I.; Camero, M.; Agulló-Rueda, F.; Gómez-Aleixandre, C. Hydrogen quantification in hydrogenated amorphous carbon films by infrared, Raman, and X-ray absorption near edge spectroscopies. J. Appl. Phys. 2009, 105, 093510. [CrossRef]

35. Colgan, M.J.; Meyyappan, M.; Murnick, D.E. Very high-frequency capacitively coupled argon discharges. Plasma Sources Sci. Technol. 1994, 3, 181-189. [CrossRef] 
36. Merlen, A.; Buijnsters, J.; Pardanaud, C. A Guide to and Review of the Use of Multiwavelength Raman Spectroscopy for Characterizing Defective Aromatic Carbon Solids: From Graphene to Amorphous Carbons. Coatings 2017, 7, 153. [CrossRef]

37. Ferrari, A.; Robertson, J. Interpretation of Raman spectra of disordered and amorphous carbon. Phys. Rev. B 2000, 61, 14095-14107. [CrossRef]

38. Zhou, X.; Suzuki, T.; Nakajima, H.; Komatsu, K.; Kanda, K.; Ito, H.; Saitoh, H. Structural analysis of amorphous carbon films by spectroscopic ellipsometry, RBS/ERDA, and NEXAFS. Appl. Phys. Lett. 2017, 110, 201902. [CrossRef]

39. Adamopoulos, G.; Robertson, J.; Morrison, N.A.; Godet, C. Hydrogen content estimation of hydrogenated amorphous carbon by visible Raman spectroscopy. J. Appl. Phys. 2004, 96, 6348. [CrossRef]

40. Casiraghi, C.; Ferrari, A.C.; Robertson, J. Raman spectroscopy of hydrogenated amorphous carbons. Phys. Rev. B 2005, 72, 085401. [CrossRef]

(C) 2019 by the authors. Licensee MDPI, Basel, Switzerland. This article is an open access article distributed under the terms and conditions of the Creative Commons Attribution (CC BY) license (http:/ / creativecommons.org/licenses/by/4.0/). 